\title{
Pemberdayaan Potensi PKK Cabawan Kota Tegal Melalui Pelatihan Pembatan Sabun Cair di Masa Pandemi Covid-19
}

\author{
Heru Nurcahyo*, Aldi Budi Riyanta, Joko Santoso \\ DIII Farmasi Politeknik Harapan Bersama \\ *Corresponding Author. Email: herunurcahyo7770@gmail.com
}

\begin{abstract}
The aims of this community service is to provide assistance and training to the PKK for the manufacture of liquid soap products based on waste oil jelantah to improve the understanding and skill of the PKK through the manufacture of liquid soap preparation forms to take a role in breaking the spread of the Covid-19 outbreak and provide motivation for the development of the creative economy. This method of implementation uses training conducted for one month in December 2020 by starting to provide materials, make preparations and evaluation of preparations to result in good liquid soap. Then for the evaluation of participants by holding pretests and posttests to see the increase in participants' knowledge. The results of this activity obtained an increase in science and understanding of the manufacture of liquid soap by $21 \%$ regarding the understanding and knowledge that has been given.
\end{abstract}

\begin{abstract}
Abstrak: Tujuan dari pengabdian masayarakat ini yaitu memberikan pendampingan dan pelatihan kepada PKK untuk pembuatan produk sabun cair berbasis limbah minyak jelantah guna meningkatkan pemahaman dan skill PKK melalui pembuatan bentuk sediaan sabun cair untuk mengambil peran dalam memutus penyebaran wabah Covid-19 serta memberikan motivasi bagi perkembangan ekonomi kreatif. Metode pelaksanaan kegiatan ini menggunakan pelatihan yang dilakukan selama satu bulan di Desember 2020 dengan diawali memberikan materi, membuat sedian dan evaluasi sediaan untuk mengahasilkan sabun cair yang baik. Kemudian untuk evaluasi peserta dengan mengadakan pretest dan posttest untuk melihat peningkatan pengetahuan peserta. Hasil dari kegiatan ini diperoleh peningkatan keilmuan dan pemahaman tentang pembuatan sabun cair sebesar $21 \%$ mengenai pemahaman dan pengetahuan yang telah diberikan.
\end{abstract}

\section{Article History:}

Received: 04-08-2021

Reviewed: 26-08-2021

Accepted: 09-10-2021

Published: 13-11-2021

\section{Key Words: \\ Empowerment, \\ Training, Liquid \\ Soap, Covid-19.}

\section{Sejarah Artikel:}

Diterima: 04-08-2021

Direview: 26-08-2021

Disetujui: 09-10-2021

Diterbitkan: 13-11-2021

Kata Kunci:

Pemberdayaan, Pelatihan, Sabun Cair, Covid-19.

How to Cite: Nurcahyo, H., Riyanta, A., \& Santoso, J. (2021). Pemberdayaan Potensi PKK Cabawan Kota Tegal Melalui Pelatihan Pembatan Sabun Cair di Masa Pandemi Covid-19. Jurnal Pengabdian UNDIKMA, 2(2), 275-280. doi:https://doi.org/10.33394/jpu.v2i2.4011

d.

https://doi.org/10.33394/jpu.v2i2.4011

This is an open-access article under the CC-BY-SA License.

\section{Pendahuluan}

Pada awal 2020, dunia dikejutkan dengan mewabahnya pneumonia baru yang kemudian menyebar dengan cepat ke lebih dari 190 negara, Wabah ini diberi nama coronavirus disease 2019 (Covid-19) yang disebabkan oleh Severe Acute Respiratory Syndrome Coronavirus-2 (SARS-CoV-2). Penyebaran penyakit ini telah memberikan dampak luas secara sosial dan ekonomi. Penurunan ekonomi juga kita rasakan sampai di Kota Tegal Jawa Tengah, tetapi Pemerintah Indonesia melalui kementerian terkait tengah menggalakan pemulihan ekonomi nasional dengan membuat program stimulus dan recovery yang diakibatkan oleh pandemi ini, salah satunya ialah dengan mengeluarkan Program Ekonomi Nasional (PEN). Disamping itu, Pemerintah bersama seluruh sektor terkait terus berupaya untuk menstimulus ekonomi masyarakat agar tetap bertahan. Stimulus ekonomi kreatif menjadi salah satu alternatif yang diandalkan dari perekonomian Indonesia. Menurut 
data dari Badan Pusat Statistik (BPS) tentang perkembangan ekonomi sejak 3 Bulanan I di Tahun 2020 menunjukkan telah terjadi Deselerasi ekonomi nasional sekitar 2,97\%. Hasil laporan dari situs Buku Warung juga menyebut terjadi penurunan pendapatan hingga 90\% pada Industri Kecil Menengah (IKM) selama empat bulan terakhir. Dapat dipastikan bahwa Pandemi Covid-19 berimbas terhadap berbagai sektor termasuk ekonomi kreatif.

Kondisi pandemi ini salah satu yang sangat dibutuhkan untuk protokol kesehatan adalah ketersediaan bahan herbal imunitas (Nurcahyo et al., 2020) dan sabun cair untuk cuci tangan, dimana kebutuhan ketersediaan sabun cuci tangan untuk masyarakat dan fasilitas umum dilingkungan Kelurahan Cabawan sangat meningkat dalam setiap harinya. Berdasarkan diskusi dengan pengurus kelompok PKK salah satu hal yang dibutuhkan kegiatan pelatihan tersebut yaitu pembuatan sabun cair khususnya untuk cuci tangan sebagai agenda lanjutan dari pelatihan sebelumnya. PKK Cabawan Kota Tegal merupakan salah satu penggerak yang sangat produktif sehingga menjadi tolok ukur pertahanan ekonomi kelurga dan bisa membatu meningkatkan penguatan ekonomi di Kota Tegal, bahkan bisa menciptakan wirausahawan-wirausahan baru, tentunya dengan manajemen bisnis yang baik (Apriansyah dkk, 2020). Kegiatan ini memiliki tujuan untuk meningkatkan pemahaman keterampilan PKK tentang penggunaan limbah minyak goreng untuk diolah menjadi sabun cair dengan harapan meningkatkan kemanfaatan dan nilai ekonomis dari hasil produk di masa pandemi.

\section{Metode Pengabdian}

Kegiatan ini terlaksana melalui beberapa tahapan metode atau langkah-langkah dalam melaksanakan solusi yang ditawarkan untuk mengatasi permasalahan tersebut. Berdasarkan permasalahan yang dihadapi PKK Cabawan Kota Tegal, maka salah satu solusi yang dapat dilakukan adalah membekali pengetahuan tentang pembuatan sediaan sabun cair berbahan baku minyak jelantah/limbah minyak goreng, memberikan pelatihan pembuatan sabun cair dan memberikan pelatihan evaluasi sediaan sabun cair (Nurcahyo \& Sumarni, 2015), (Nurcahyo, 2021). Tahapan metode dalam kegiatan ini digambarkan pada gambar 1 berikut.

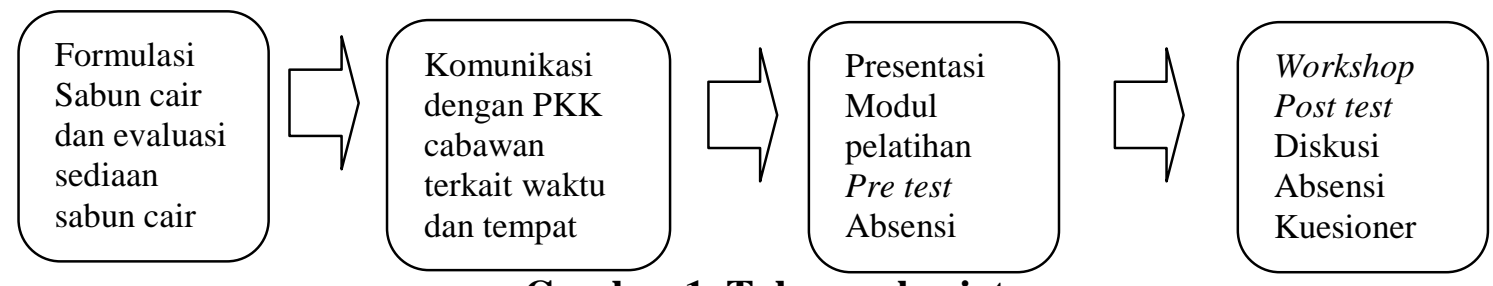

Gambar 1. Tahapan kegiatan

Tahap formulasi dilaksanakan di Laboratorium Teknologi Farmasi milik Prodi Farmasi Politeknik Harapan Bersama. Pembuatan modul yang digunakan dalam pelatihan. Modul yang dimaksud dibuat oleh panitia pelaksana (trainer) dengan cakupan berupa materimateri yang diberikan dalam pelatihan. Modulnya dibuat dalam bentuk tutorial dan teori dengan maksud untuk memudahkan peserta dalam pemahaman materi.

Tahap persiapan dengan komunikasi PKK Cabawan Kota Tegal untuk menentukan waktu dan jam pelaksanaan serta mejelaskan metode yang digunakan. Mempersiapkan media presentasi interaktif yaitu slide presentasi yang dibuat oleh trainer termasuk infocus/ LCD Proyektor dan materi pendukung lainnya yang akan dibutuhkan oleh peserta, seperti training kit (modul, daftar hadir, dan sertifikat), memastikan kelengkapan konsumsi, dan berkas pendukung lainnya. Mempersiapkan alat dan bahan yang digunakan dalam pelatihan, yaitu bahan formulasi, alat glas, dan alat uji sediaan sabun cair. 
Tahap pelasanaan dengan metode pendekatan yang ditawarkan untuk menyelesaikan persoalan yang telah disepakati bersama adalah mengadakan presentasi materi, diskusi, dan tanya jawab. Dalam sesi materi ini, peserta didata ulang berdasarkan informasi yang diperoleh pada saat pendaftaran. Sebelum materi dimulai, masing-masing peserta diberi alat tulis serta modul pelatihan. Dalam kegiatan ini PKK diberikan pretes aal untuk mengetahui tingkat pemahaman tentang sediaan sabun cair.

Tahap pelaksanaan kegiatan pelatihan ini, tim memberikan pendampingan dalam membuat sediaan sambil mengulang informasi meteri atau tahapan-tahapan dalam pembuatan sediaan yang sudah diberikan hari sebelumnya, kegiatan pelatiha ini memiliki target setiap peserta anggota PKK dan laboran memiliki kemampuan yang sama untuk membuat sabun cair dengan baik sesui prosedur pada materi yang sudah diberikan. Selanjutnya diberikan materi pendalam tentang sediaan tersebut dan di akhir sesi tahap pertama diberikan postest tentang materi yang diberikan untuk mengukur tingkat pencapaian pemahaman yang diberikan dalam pelatihan.

\section{Hasil Pengabdian dan Pembahasan}

Kegiatan pengabdian ini terlaksana antara Prodi D3 Farmasi PHB yang beralamat di Jl. Mataram No 9 Kota Tegal dan Balai Kelurahan Cabawan Kota Tegal, dimana kegiatan ini diawali dengan adanya surat permintaan dari PKK untuk memberikan workshop pembuatan sediaan sabun cair, selanjutnya diadakan kegiatan survay untuk mengetahui data perserta, kebutuhan pelatihan, tempat pelatihan dan jawaban dari surat yang merupakan tindak lanjut dari kegiatan tersebut. Pelaksanaan kegiatan ini direncanakan pada tanggal 1 sampai 15 Desember 2020, dilanjutkan kegiatan pada tanggal 18-19 Desember 2020 dan diakhiri dengan agenda evaluasi kegiatan pada tanggal 23 desember 2020 dengan rincian kegiatan pelaksanaan sebagai berikut:

Hari pertama, dilaksanakan pada tanggal 18 Desember 2020, jam 9 sd jam 12 wib, diawali dengan mengecek kelengkapan dan persiapan pelaksanaan kegiatan PKM, dimana kegiatan dilaksanakan dilaboratorium Prodi D3 Farmasi PHB dengan praktek membuat sabun cair yang dilaksanakan oleh tim PKM terdiri mahasiswa, dosen dan laboran. Kegiatan tersebut untuk memastikan tentang modul dan prosedur yang sudah disusun sesuai sehingga dapat menghasilkan produk sabun cair yang baik (Zein et al., 2016), (Naomi \& Gaol, 2013), (Rahayu \& Purnavita, 2014). Selanjutnya diadakan survay peserta dan lokasi kegiatan pada hari kedua dengan PKK Cabawan Kota Tegal.

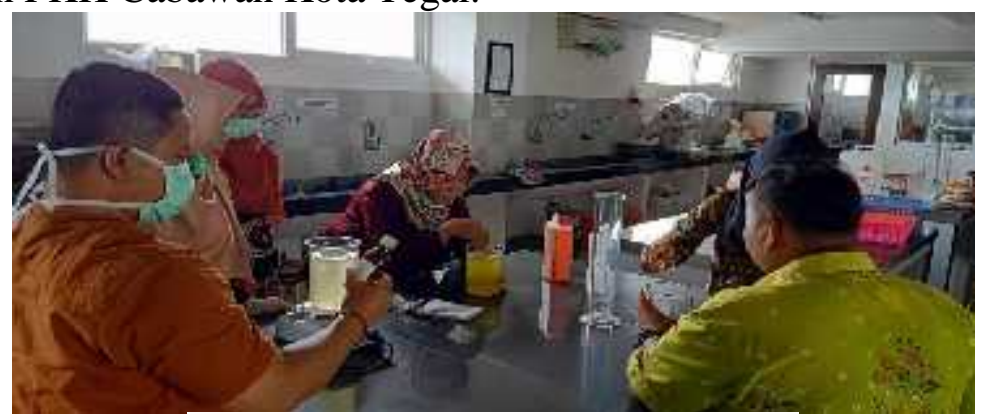

Gambar 2. Formulasi Sabun Cair.

Hari Kedua tahap pertama, tanggal 19 Desember 2020, jam 8 sampai dengan jam 12 diawali dengan mendata ulang data peserta, absensi, pretest dan dilanjutkan materi, setelah diberikan pendalaman tentang materi pembuatan sediaan sabun cair, peserta juga dijelaskan karakteristik bahan yang akan digunakan dalam pembuatan sediaan. 
Mengawali kegiatan pada hari pertama dengan pre test, yang bertujuan untuk mengukur kemampuan peserta, khususnya yang berkaitan dengan soal-soal mendasar tentang sediaan sabun cair, karakteristik bahan, cara pembuatan dan evaluasi sediaan. Hasil dari pre test dijadikan sebagai pembanding tingkat keberhasilan tim dalam memberi workhop kepada peserta. Selain itu, hasil tersebut juga digunakan untuk melihat peningkatan pemahaman materi bagi PKK sehingga peningkatan pemahaman pasca pemberian materi serta untuk memudahkan dalam menyiapkan kegiatan pada tahap kedua.

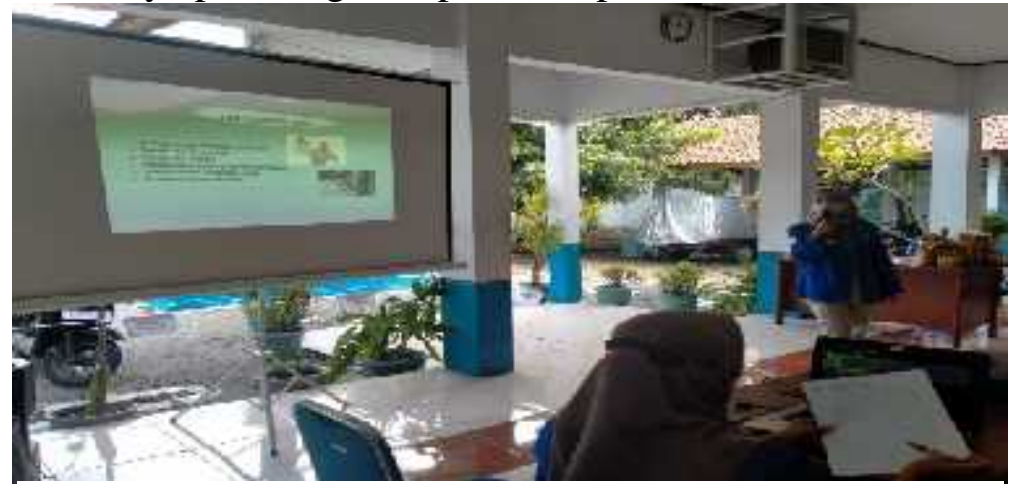

\section{Gambar 3. Pelaksanaan Presentasi Pendalaman Materi}

Pemberian materi diberikan secara mendalam kepada peserta untuk menngkatkan kompetensinya seperti pada pembuatan formulasi, dimana dikenalkan tentang karakteristik bahan, karakteristik bentuk sediaan seperti cairan dan gel, membaca literasi hand book untuk penentuan standar formula serta pengujiaan sediaan sehingga hasilnya nanti dapat dipertanggungjawabkan dan siap dibagikan kepada masyarakat. Dalam kegiatan tersebut mitra juga diberikan edukasi tentang covid-19 sehingga diharapkan ada upgrade pengetahuan dalam rangka turut serta untuk memutus mata rantai penyebaran wabah tersebut.

Pelaksanaan pembuatan sabun cair secara seksama dilakukan oleh tim PKM dengan PKK cabawan secara berkelompok sesuia dengan formulasi dan prosedur yang sudah diberikan, TIM PKM memberikan arahan agar pelaksanaan pembuatan berjalan sesuai dengan prosedur serta memberikan pencejalan dari tahapan pembuatan sediaan tersebut. Kegiatan pembuatan sabun cair dengan bahan jelantah minyak goreng dapat diliat pada Gambar 4.

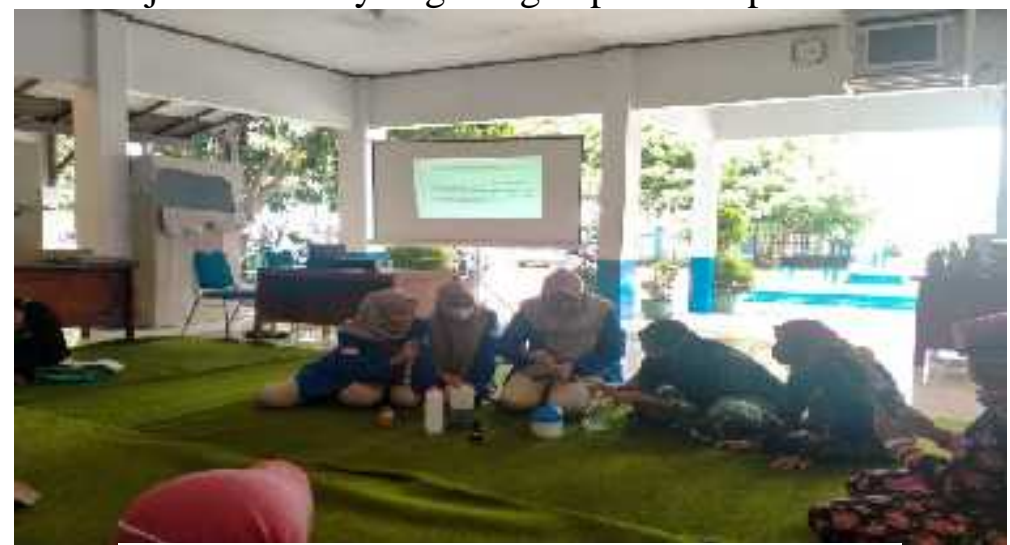

Gambar 4. Pembuatan Sediaan Sabun Cair.

Setelah membuat sediaan sabun cair hasil praktek PKK dilakukan packing dengan wadah yang sudah disiapkan, harapannya kegiatan tersebut dapat memberikan inspirasi bagi kegiatan PKK Cabawan Kota Tegal sehingga dapat diprakteknya masing-masing dirumah dan hasilnya bisa digunakan untuk protokol kesehatan sebagai sabun cuci tangan. 


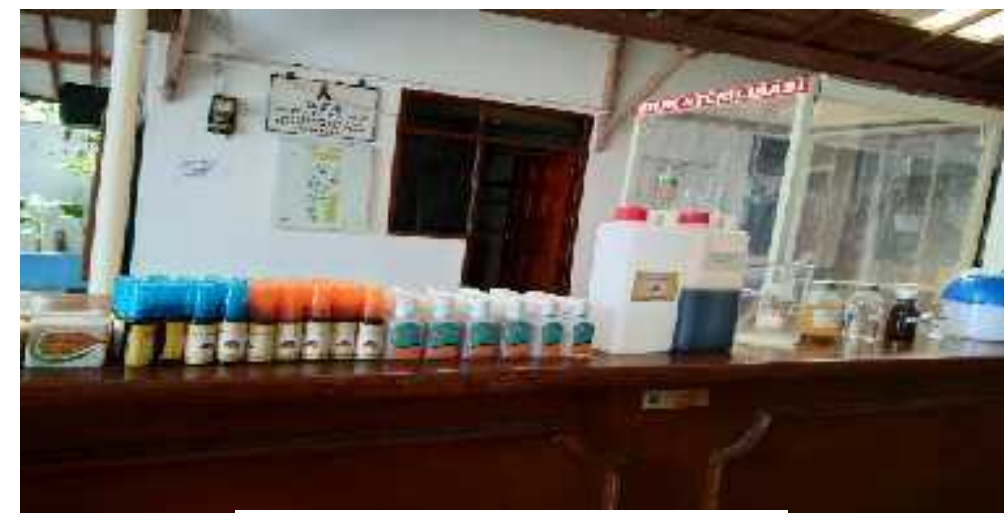

Gambar 5. Produk Sabun Cair

Hari kedua tahap Kedua, dilaksanakan jam 13.00 sampai dengan jam 16.00 wib, dilakukan evaluasi hasil pembuatan sabun cair dan setelah kegiatan evaluasi dilakukan sesi post test, dijadikan sebagai evaluasi oleh tim pelaksana, yaitu dengan membandingkan hasil post test dengan pre test untuk mengetahui nilai peningkatan pemahamannya serta kepuasan kegiatan (Nurcahyo \& Sumarni, 2015). Hasil peningkatan nilai pemahaman dapat dilihat pada Gambar 6.

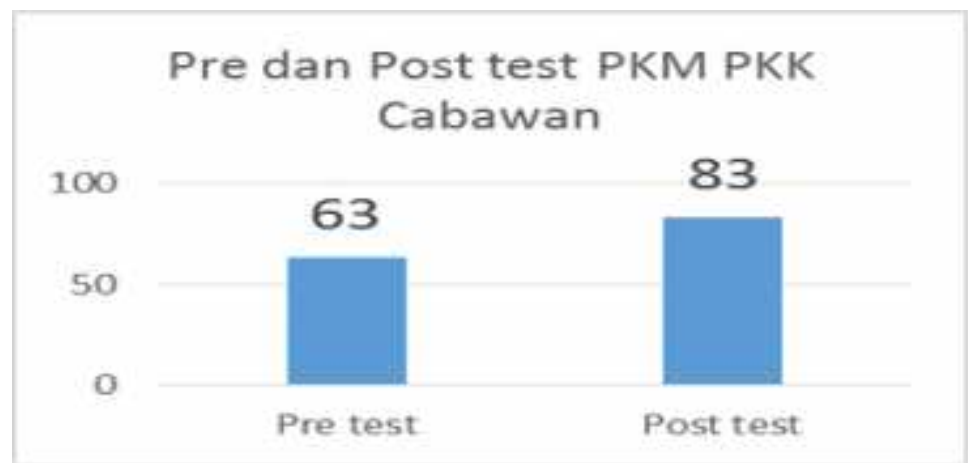

Gambar 6. Prosentase Hasil Pre test dan Post test Kegiatan PKM

Hasil kegiatan pre test mendapatkan nilai rata-rata 63 dan hasil post test mendapatkan nilai rata-rata 83, terjadi peningkatan pemahaman sejumlah $20 \%$ sebagai persiapan untuk melahkan pada kegiatan workshop dihari selanjutnya.

Kegiatan penutupan PKM diisi dengan diskusi untuk peningkatan perbaikan kegiatan berikutnya. Tim juga memberikan memotivasi kepada para peserta pelatihan agar terus belajar dan meningkatkan kompetensi baik secara individu maupun kelompok. Hal itu dilakukan dengan harapan agar PKK dapat memanfaatkan modul pelatihan tersebut untuk warga masyarakat agar didapatkan peningkatan skill pembuatan sediaan sabun cair. Hasil evaluasi dari kegiatan tersebut pengurus PKK akan dijembatani untuk pembuatan sediaan berkelanjutan yang memiliki nilai jual dengan melanjutkan kegiatan bekerjasama dengan Prodi DKV (Desain Komunikasi Visual) terkait bentuk sediaan serta pelatihan tentang manajemen penjualan dengan Prodi D3 Akuntansi, dimana kegiatan tersebut akan menjadi agenda yang terstruktuk untuk mengawal kegiatan PKK khususnya pembuatasan sediaan sabun cair tidak hanya bermanfaat untuk protokol kesehatan bagi keluarga dan fasilitas umum tetapi juga bisa dimanfaatkan untuk ekonomi kreatif. 


\section{Kesimpulan}

Pelaksanaan kegiatan pengabdian kepada masyarakat ini sudah sesuai dengan tujuan yaitu meningkatkan pemahaman dan skill PKK melalui pembuatan bentuk sediaan sabun cair untuk mengambil peran dalam memutus penyebaran wabah Covid-19 serta memberikan motivasi bagi perkembangan ekonomi kreatif. Dengan pelatihan dapat meningkatan pemahaman dan kemampuan PKK dalam mendalami materi tersebut kususnya pada pembuatan sediaan sabun dari limbah minyak jelantah sampai dengan menghasilkan produk dengan kuliatas baik dan dari hasil evaluasi pre test dan post test didapatkan peningkatan nilai sebesar $20 \%$.

\section{Saran}

Saran yang dapat disampaikan berdasarkan hasil kegiatan pengabdian ini adalah perlu diadakan pemantauan dan kegiatan kegiatan yang berkelanjutan dengan tema-tema baru untuk meningkatkan kompetensi PKK seperti desain sediaan serta metode penjualan produk tersebut, dengan harapan peningkatan kemampuan tersebut dapat diterapkan untuk peningkatan inovasi ekonomi kreatif.

\section{Daftar Pustaka}

Apriansyah, Muger., Sahroni., Sutoro, Moh., Mukrodi., Krisyanto, E. (2020). Membangun Spirit Kewirausahaan Sebagai Langkah Positif Di Masa Pandemi Pada. Jurnal Pengabdian Kepada Masyarakat, 1 (September).

Naomi, P., \& Gaol, A. M. L. (2013). Naomi, Phatalina Gaol, Anna M Lumban. Jurnal Teknik Kimia, 19(2), 42-48.

Nurcahyo, H., \& Sumarni. (2015). Hubungan Kualitas Pelayanan Rawat Jalan Pada Era Jaminan Kesehatan Nasional Terhadap Kepuasan Pasien. Jurnal Manajemen Dan Pelayanan Farmasi, 5(2), 2-6.

Nurcahyo, H., Sumiwi, S. A., Halimah, E., \& Wilar, G. (2020). Total Flavonoid Levels of Ethanol Extract and Ethyl Acetate Fraction Dry Shallots (Allium cepa L. var. Garden Onion of Brebes) with Maceration Methods Using UV-Vis Spectrophotometry. Systematic Reviews in Pharmacy, 11(10), 286-289. https://doi.org/10.31838/srp.2020.10.48

Rahayu, L., \& Purnavita, S. (2014). Pengaruh Suhu Dan Waktu Adsorpsi Terhadap Sifat Kimia-Fisika Minyak Goreng Bekas Hasil Pemurnian Menggunakan Adsorben Ampas Pati Aren Dan Bentonit. Jurnal Momentum UNWAHAS, 10(2), 115187.

Zein, R., Silfia, Afriyanti, N., Girsang, E., \& Aziz, H. (2016). Improvement in quality of used palm oil by rice husk ash. Research Journal of Pharmaceutical, Biological and Chemical Sciences, 7(3), 1338-1348. 